\title{
Women with Hemophilia: Case Series of Reproductive Choices and Review of Literature
}

\author{
Shadan Lalezari ${ }^{1}$ Assaf A. Barg ${ }^{1,2,3}$ Rima Dardik $^{1}$ Jacob Luboshitz ${ }^{1}$ Dalia Bashari ${ }^{1}$ Einat Avishai ${ }^{1}$ \\ Gili Kenet ${ }^{1,2,3}$
}

${ }^{1}$ National Hemophilia Center, Sheba Medical Center, Tel Hashomer, Israel

${ }^{2}$ Sackler Faculty of Medicine, Tel Aviv University, Tel Aviv, Israel

${ }^{3}$ Amalia Biron Research Institute of Thrombosis and Hemostasis,

Sheba Medical Center, Tel Hashomer, Israel

Address for correspondence Shadan Lalezari, MD, National Hemophilia Center, Sheba Medical Center, Tel Hashomer, 52621, Israel (e-mail: shadan.lalezari@sheba.health.gov.il).

TH Open 2021;5:e183-e187.

\begin{abstract}
Keywords

- hemophilia

- carriers

- women

- pregnancy

- childbirth

- reproduction
\end{abstract}

\section{Introduction}

Hemophilia A (HA) occurs in 1:5,000 live male births. As HA is a recessive $\mathrm{X}$-linked disorder, it is historically considered a disease affecting males. Females may be heterozygous for the mutation and referred to as hemophilia carriers. The carriers are expected to have plasma concentrations of factor VIII (FVIII) approximately half the concentration of healthy individuals, providing adequate hemostasis. ${ }^{1}$ However, a wide range of clotting factor levels is seen in carriers and those with FVIII activity $<0.6 \mathrm{IU} / \mathrm{mL}$ may be symptomatic with various bleeding manifestations, ${ }^{1}$ despite a level of 0.4 $\mathrm{IU} / \mathrm{mL}$ being the upper limit defining hemophilia. ${ }^{2}$ The bleeding symptoms may include cutaneous bruising and

received

February 14, 2021

accepted after revision

April 6, 2021
DOI https://doi.org/

10.1055/s-0041-1730036.

ISSN 2512-9465. hematomas, heavy menstrual bleeding, hemorrhagic ovarian cysts, hemarthrosis, a higher risk of prolonged bleeding after operations, tooth extractions, and increased risk of postpartum hemorrhage (PPH). ${ }^{1,3-5}$ This risk is inversely correlated with plasma FVIII levels. ${ }^{1,4}$

There are different estimations of hemophilia prevalence in women. Some estimate that $1: 100,000$ women is a symptomatic HA carrier. ${ }^{6}$ However, severe HA $(\mathrm{FVIII}<0.01 \mathrm{IU} / \mathrm{mL})$, a condition that places a woman at risk of severe bleeding complications, is an extremely rare event. This phenotype may stem from extreme lyonization (inactivation) of the unaffected $X$ chromosome, partial or complete monosomy of the $\mathrm{X}$ chromosome (Turner syndrome) and compound heterozygosity or homozygosity in female progeny of hemophilia

(c) 2021. The Author(s).

This is an open access article published by Thieme under the terms of the Creative Commons Attribution License, permitting unrestricted use, distribution, and reproduction so long as the original work is properly cited. (https://creativecommons.org/licenses/by/4.0/)

Georg Thieme Verlag KG, Rüdigerstraße 14, 70469 Stuttgart, Germany 
carriers and affected hemophiliac male. There are cases of other rare occurrences of hemophilia in females such as phenotypic females with testicular feminization (46XY), combined factor $\mathrm{V}$ and FVIII deficiency and acquired hemophilia. $^{7}$

As pregnancy and delivery among women with hemophilia are extremely rare, we examined the reproductive choices of female hemophilia patients at our hemophilia treatment center (HTC). Additionally a literature search and review has been conducted and is presented here.

\section{Methods and Case Reports}

The Israel National Hemophilia Treatment Center follows and treats approximately 600 HA patients. Among these are five females who were diagnosed at an early age with moderate to severe HA. Genotyping has shown that one patient is $45 \times 0$, Turner syndrome. The other four patients are hemophiliacs due to extreme lyonization of their unaffected $\mathrm{X}$ chromosome. Three of these women chose to have children and we hereby present their different ways to accomplish motherhood. All three women are followed and treated at our center and received a comprehensive multidisciplinary care by genetic counselors, obstetricians, hematologists, and the psychosocial team before and during pregnancy and after childbirth.

We reviewed the medical records of our three female HA patients who are mothers. Clinical history, family history, FVIII activity, and genetic analyses were collected. Documentation was obtained regarding reproductive decisions, pregnancy follow-up, delivery, postpartum course, and offspring outcomes. The retrospective study of patients' medical files from our computerized database was approved by our institutional review board in concordance with the Declaration of Helsinki.

\section{Patient \#1}

Patient was born to a father with severe HA. She was diagnosed with moderate HA (FVIII level: 4\%) at the age of 2 years, due to cutaneous hematomas and a joint bleed. The genetic analysis revealed intron 22 inversion with extreme lyonization of the other X-chromosome. At the age of 6 years, she was diagnosed with a brain tumor and underwent craniotomy for tumor removal, followed by chemotherapy and radiotherapy.

In the 1970 s, as a young hemophilia patient, she was treated with cryoprecipitate and plasma-derived FVIII and was infected with human immunodeficiency virus (HIV) and hepatitis $\mathrm{C}$ virus (HCV). Her viral load has been minimal since the introduction of antiretroviral therapy with a normal CD4/CD8 ratio. She was later treated for HCV and achieved a complete viral response. She continued with mainly on demand treatment for her rare hemarthroses, with prophylaxis before surgical and dental procedures.

At the age of 28 , the patient became pregnant following in vitro fertilization (IVF) with preimplantation genetic diagnosis (PGD). However, pregnancy was terminated due to marked elevation of liver enzymes and the couple was obliged to refrain from further attempts. At the age of 30 they adopted a healthy infant. A few years later, they had twins from IVF utilizing egg donations with the husband's sperm. This was materialized through a surrogate mother.

\section{Patient \#2}

This patient with hypothyroidism and sporadic moderate HA (FVIII level: 3\%) is known to our hemophilia center since early infancy due to recurrent hemarthrosis. She was later found to be a carrier of intron 22 inversion with extreme inactivation of the other $\mathrm{X}$ chromosome. As family history was negative for hemophilia and the mutation was not found in her father's peripheral blood DNA, it was postulated that the mutation was either a de novo germ cell mutation or germ cell or somatic mosaicism. ${ }^{7-9}$ Paternity was confirmed through genetic linkage analysis.

This patient suffered from recurrent hemorrhagic ovarian cysts whenever she stopped oral contraceptives. Menstruation was controlled with oral contraceptives and occasional FVIII replacement in the beginning of the menses.

Once she was married, the options regarding conception were discussed, prenatal diagnosis or IVF with PGD were offered. Yet she conceived spontaneously at the age of 24 years, refusing any intervention or diagnostic evaluation of the hemophilia status of the male embryo.

She received intravenous (IV) prophylactic recombinant FVIII 2,000 IU (35 IU/kg) every other day since early pregnancy. Her plasma FVIII trough levels were in the range of 10 to $20 \mathrm{IU}$ during pregnancy. She was followed at our hemophilia center and at high-risk pregnancy unit for prenatal care.

Toward the end of her pregnancy, delivery options were discussed to protect both the mother and the potentially hemophiliac male newborn. Vaginal delivery was planned, with the intent to switch to a cesarean section early in the course of any complication, avoiding instrumental delivery. However, a semi-elective cesarean section was performed at 38 weeks' gestation under general anesthesia. She received an IV FVIII bolus of 2,000 units, yielding a FVIII level of 95 IU at commencement of surgery. In addition, she received IV $1,000 \mathrm{mg}$ tranexamic acid and local fibrin sealants were applied on the surgery surfaces. Postdelivery FVIII and tranexamic acid were continued for 2 weeks and then regular prophylaxis was resumed. The baby was diagnosed with severe HA. Currently both mother and child are being followed at our center and both receive FVIII prophylaxis.

\section{Patient \#3}

This is a 35-year-old patient with severe familial HA (her father and her paternal uncle were both treated at our center with an IVS $5+2 \mathrm{~T}>\mathrm{G}$ splice site mutation).

She was diagnosed with severe HA at an early age due to hemarthrosis. Most of her life she received on-demand treatment for bleeds, mainly joint bleeds.

Prior to pregnancy she underwent a thorough genetic investigation and counseling and chose to proceed with IVF with PGD with a female embryo not carrying the FVIII gene mutation. 
She started prophylaxis with IV FVIII 2,000 units (35 units/kg) twice weekly from early pregnancy, with FVIII trough levels in the range of 3 to 7 IU. Her pregnancy was uneventful until the 38th week when she was hospitalized with preeclampsia. Following administration of $1,000 \mathrm{mg}$ tranexamic acid and an IV bolus of 2,000 IU FVIII, resulting in a FVIII level of 82 IU, an epidural anesthesia was performed. She underwent emergency cesarean section due to nonreassuring fetal monitoring and meconial water. Intensified prophylaxis was maintained for the first week and tranexamic acid was continued for a total of 2 weeks.

\section{Discussion}

Literature regarding pregnancy and delivery in women with hemophilia is sparse reflecting the rarity of this event.

The patients in the current study were offered genetic counseling prior to conception to enable them to have healthy offsprings. This can be achieved by prenatal diagnosis of spontaneous pregnancies (and considering termination of pregnancy in case of severe hemophiliac fetus) or IVF with PGD.

Patient \#1 faced additional challenges due to her HIV and HCV infection. Notably, assisted reproductive technologies are offered for HIV serodiscordant couples with hemophilia. ${ }^{10,11}$ Following an unsuccessful pregnancy attempt, they chose to adopt and later had twins from donor oocytes, inseminated by the husband's sperm and a surrogate mother. Thus they materialized their wish to have a family and they put an end to the hemophilia gene in their progeny.

Patient \#2 is an orthodox Jew and chose to avoid any interference with natural reproduction. Indeed, often the decisions made by hemophilia carriers are influenced by the families' cultural and religious background. ${ }^{12}$ Patient \#3 chose to undergo IVF with PGD to ensure a nonhemophiliac offspring. It has been suggested that previous hemophilia experience may affect reproductive choices. ${ }^{13}$ Interestingly, other family members of this patient suffered from severe consequences of hemophilia.

In the current study, all three women were hemophiliacs due to extreme lyonization. This is an extremely rare event of marked nonrandom inactivation of the X-chromosome. Extreme lyonization in a carrier of HA may indicate carrier status of several X-linked disorders on the nonhemophiliac X chromosome, including mental retardation and immune disorders. ${ }^{14}$ Thus, in cases of women with severe hemophilia due to extreme lyonization, establishing a genetic cause of the nonrandom skewing is of great importance, as the male offspring will either be hemophiliac or at risk of another $\mathrm{X}$-linked disease. The female offsprings will either be carriers of hemophilia or carriers of another X-linked disease. The maternal skewed $X$ chromosome will probably be silenced in the female progeny. However, her sons, carrying the nonhemophilic X chromosome, may be inflicted by a serious disease.

Patient \#3 chose a female fetus carrying her extremely skewed X chromosome, assuming that it will be lyonized in the female offspring, as it was in the patient and her mother. Extreme lyonization was confirmed in the female baby after birth. One may argue that carrying a hemophilia gene was a safer decision rather than choosing the $\mathrm{X}$ chromosome harboring another unknown disease. This is especially relevant nowadays as hemophilia is a treatable and perhaps a curable disease. $^{15}$

Lusher et al reported on four deliveries of four women with moderate to severe HA, one of them had excessive bleeding during and after delivery, necessitating blood transfusions. However, there is no information regarding mode of analgesia, delivery, and peripartum treatment of these women. ${ }^{16}$ - Table 1 summarizes the latter case reports from the literature and our two patients who became pregnant and delivered. ${ }^{6,17,18}$

The risk of bleeding in early pregnancy is unknown in carriers of hemophilia. The risk of miscarriage in this population was reported to be $31 \%$ (vs. $12-13.5 \%$ in the general population), with the risk of antepartum hemorrhage not increased. ${ }^{19}$ One should keep in mind that as pregnancy progresses, FVIII levels increase in pregnant women. In hemophilia carriers with borderline FVIII levels, this increase can normalize the FVIII levels. However, in women with moderate to severe HA, this increase is not sufficient to allow for delivery without replacement therapy. ${ }^{20}$ We initiated prophylaxis during first trimester and continued FVIII replacement throughout the pregnancies. None of our patients experienced any bleeds during pregnancy in concordance with previous published reports ( $\mathbf{- T a b l e} \mathbf{1}$ ).

In the guidelines regarding labor of women with inherited bleeding disorders, ${ }^{21}$ regional anesthetic block is not contraindicated provided normal coagulation screen and the relevant factor level above $50 \mathrm{IU} / \mathrm{dL}$. Indeed, one of our patients gave birth under general anesthesia and one with an epidural block. There is a case report on one other woman with hemophilia who gave birth with an epidural block ${ }^{6}$ while the other four women gave birth under general anesthesia (-Table $\mathbf{1}$ ).

The safest method of delivery of fetuses at risk of having a coagulation disorder is still controversial. ${ }^{22}$ Davies and Kadir reported that vaginal delivery is associated with an increased risk of intracranial hemorrhage (ICH) as compared with cesarean section. However, a recent PedNet study showed that vaginal delivery and cesarean section carry similar risks for $\mathrm{ICH}$ and other major bleeds. ${ }^{23}$

When fetal sex or coagulation status is unknown, or in case of an affected male fetus, the use of any invasive monitoring, and instrumental delivery are contraindicated. Among the six deliveries presented in - Table 1, three deliveries were vaginal and three cesarean sections were performed.

Hemophilia carriers are at increased risk of both primary ( $>500 \mathrm{~mL}$ blood loss within the first 24 hours) and secondary (after the first 24 hours) PPH, with an incidence of 19 and $2 \%$ respectively as opposed to $5-8 \%$ and $0.8 \%$ in the general population. ${ }^{20}$ Regular follow-up at HTC and high-risk pregnancy units and having a delivery plan prepared in advance reduce the occurrence of peripartum complications. Our patients continued treatment with FVIII aiming at levels above $50 \mathrm{IU} / \mathrm{dL}$ in the first 3 days postvaginal delivery and the first 5 days post cesarean section, in accordance with guidelines ${ }^{21}$ and then were gradually treated with smaller doses and less frequently 
Table 1 Case reports of pregnancy management, labor, and postpartum treatment of women with HA

\begin{tabular}{|c|c|c|c|c|c|c|}
\hline & $\begin{array}{l}\text { Hemophilia } \\
\text { severity }\end{array}$ & $\begin{array}{l}\text { IV FVIII Tx } \\
\text { during } \\
\text { pregnancy }\end{array}$ & Delivery & Analgesia & IV FVIII Tx-delivery and postpartum & Offspring \\
\hline Dhar et al ${ }^{6}$ & Severe & $\begin{array}{l}\text { Prophylaxis } \\
30 \mathrm{IU} / \mathrm{kg} \times 2 / \text { week }\end{array}$ & $\begin{array}{l}\text { Spontaneous } \\
\text { vaginal }\end{array}$ & Epidural & $\begin{array}{l}\text { Bolus } 50 \mathrm{IU} / \mathrm{kg} \text { then } \\
\mathrm{IV} \mathrm{CI} 3 \mathrm{IU} / \mathrm{kg} / \mathrm{h} \text { for } 3 \text { days, } \\
\text { then regular prophylaxis }\end{array}$ & $\begin{array}{l}\text { Female, not } \\
\text { hemophilia carrier }\end{array}$ \\
\hline $\begin{array}{l}\text { Sharma et al } \\
\text { ( } 2 \text { pregnancies } \\
\text { of the same } \\
\text { woman) }\end{array}$ & Severe & $\begin{array}{l}\text { Prophylaxis } \\
40 \mathrm{IU} / \mathrm{kg} \times 2 / \mathrm{wk}\end{array}$ & $\begin{array}{l}\text { Induced } \\
\text { vaginal }\end{array}$ & $\begin{array}{l}\text { General } \\
\text { anesthesia }\end{array}$ & $\begin{array}{l}25 \mathrm{IU} / \mathrm{kg} \times 3 / \text { day } 25 \mathrm{IU} / \mathrm{kg} \times 2 / \text { day } \\
\text { (days } 2-5), 25 \mathrm{IU} / \mathrm{kg} / \mathrm{d} \text { (days } 6-14) \text {, } \\
\text { every other day for another } 4 \text { weeks }\end{array}$ & $\begin{array}{l}\text { Female, } \\
\text { female }\end{array}$ \\
\hline $\begin{array}{l}\text { Bodrozic } \\
\text { et al }^{18}\end{array}$ & Severe & $\begin{array}{l}\text { On demand for } \\
\text { bleeds } 20 \mathrm{IU} / \mathrm{kg}\end{array}$ & $\begin{array}{l}\text { Planned } \\
\text { cesarean } \\
\text { section }\end{array}$ & $\begin{array}{l}\text { General } \\
\text { anesthesia }\end{array}$ & $\begin{array}{l}50 \mathrm{IU} / \mathrm{kg} \text { predelivery. } \\
\text { Postdelivery: } \\
30 \mathrm{IU} / \mathrm{kg} \times 2 / \text { day for } 6 \text { days, tranexamic } \\
\text { acid (for } 6 \text { weeks) and hormonal } \\
\text { contraceptives }\end{array}$ & $\begin{array}{l}\text { Female, not } \\
\text { hemophilia carrier }\end{array}$ \\
\hline PT \#2 & Moderate & $\begin{array}{l}\text { Prophylaxis } \\
35 \mathrm{IU} / \mathrm{kg} \times 3 / \mathrm{wk}\end{array}$ & $\begin{array}{l}\text { Semi-elective } \\
\text { cesarean }\end{array}$ & $\begin{array}{l}\text { General } \\
\text { anesthesia }\end{array}$ & $\begin{array}{l}2,000 \text { IU FVIII } \times 2 \text { on day of delivery, } \\
2,000 \text { IU } \times 1 / \text { day for a week and every } \\
\text { other day for another week, } \\
\text { tranexamic acid } 1 \mathrm{gr} \times 3 / \text { day for } 2 \text { weeks }\end{array}$ & Male hemophiliac \\
\hline PT \#3 & Severe & $\begin{array}{l}\text { Prophylaxis } \\
35 \mathrm{IU} / \mathrm{kg} \times 2 / \mathrm{wk}\end{array}$ & $\begin{array}{l}\text { Emergency } \\
\text { cesarean } \\
\text { section }\end{array}$ & Epidural & $\begin{array}{l}2,000 \mathrm{IU} \times 2 \text { on day } 0 \text {, then } \\
2,000 \mathrm{IU} \times 1 / \text { day for } 3 \text { days, } \\
2,000 \mathrm{IU} \text { every other day for a } \\
\text { week }+ \text { tranexamic acid for } 2 \text { weeks }\end{array}$ & $\begin{array}{l}\text { Female, not } \\
\text { hemophilia carrier }\end{array}$ \\
\hline
\end{tabular}

Abbreviations: $\mathrm{Cl}$, continuous infusion; FVIII, factor VIII; IU, international units; IV, intravenous; Tx, treatment.

until 2 weeks postdelivery when regular prophylaxis was resumed.

The current small cohort of females with moderate to severe HA presents a variety of reproductive issues. Our data support the adequacy of guidelines regarding pregnancy and delivery for the unique group of women with hemophilia. Materializing the women's wish to motherhood can be achieved safely with multidisciplinary care of the women and their newborns.

\section{Disclosures}

All authors have no competing interests except for: Shadan Lalezari has received honoraria/consultation fees from Bayer, Pfizer, Teva, Takeda, Roche, and PI Healthcare.

Assaf A. Barg has received honoraria for lectures from ROCHE and a grant from Pfizer.

Gili Kenet receives grant and research support from Alnylam, Bayer, BPL, Opko Biologics, Pfizer, and Shire, and honoraria for consultancy/lectures from Alnylam, Bayer, CSL, Opko Biologics, Pfizer, Takeda, and ROCHE.

\section{Author Contributions}

All authors made substantial contributions to the conception or design of the work, or the acquisition, analysis, or interpretation of data for the work. They drafted the work or revised it critically for important intellectual content. The authors approved the version to be published and agreed to be accountable for all aspects of the work in ensuring that questions related to the accuracy or integrity of any part of the work are appropriately investigated and resolved

\section{Conflict of Interest}

None declared.

\section{References}

1 Plug I, Mauser-Bunschoten EP, Bröcker-Vriends AH, et al. Bleeding in carriers of hemophilia. Blood 2006;108(01):52-56

2 White GC II, Rosendaal F, Aledort LM, Lusher JM, Rothschild C, Ingerslev JFactor VIII and Factor IX Subcommittee. Definitions in hemophilia. Recommendation of the scientific subcommittee on factor VIII and factor IX of the scientific and standardization committee of the International Society on Thrombosis and Haemostasis. Thromb Haemost 2001;85(03):560

3 Miesbach W, Alesci S, Geisen C, Oldenburg J. Association between phenotype and genotype in carriers of haemophilia A. Haemophilia 2011;17(02):246-251

4 Paroskie A, Gailani D, DeBaun MR, Sidonio RF Jr. A cross-sectional study of bleeding phenotype in haemophilia A carriers. Br J Haematol 2015;170(02):223-228

5 James AH. More than menorrhagia: a review of the obstetric and gynaecological manifestations of bleeding disorders. Haemophilia 2005;11(04):295-307

6 Dhar P, Abramovitz S, DiMichele D, Gibb CB, Gadalla F. Management of pregnancy in a patient with severe haemophilia $\mathrm{A}$. $\mathrm{Br}$ J Anaesth 2003;91(03):432-435

7 Pavlova A, Brondke H, Müsebeck J, Pollmann H, Srivastava A, Oldenburg J. Molecular mechanisms underlying hemophilia A phenotype in seven females. J Thromb Haemost 2009;7(06):976-982

8 Leuer M, Oldenburg J, Lavergne JM, et al. Somatic mosaicism in hemophilia A: a fairly common event. Am J Hum Genet 2001;69 (01):75-87

9 Oldenburg J, Rost S, El-Maarri O, et al. De novo factor VIII gene intron 22 inversion in a female carrier presents as a somatic mosaicism. Blood 2000;96(08):2905-2906

10 Pena JE, Klein J, Thronton MH, Sauer MV. Providing reproductive care to male haemophiliacs infected with human immunodeficiency virus: preliminary experience. Blood 2000;96:2905-2906

11 Oyesiku JO, Turner CF. Reproductive choices for couples with haemophilia. Haemophilia 2002;8(03):348-352

12 Kadir RA, Sabin CA, Goldman E, Pollard D, Economides DL, Lee CA. Reproductive choices of women in families with haemophilia. Haemophilia 2000;6(01):33-40

13 Tedgård U, Ljung R, McNeil TF. Reproductive choices of haemophilia carriers. Br J Haematol 1999;106(02):421-426 
14 Belmont JW. Insights into lymphocyte development from Xlinked immune deficiencies. Trends Genet 1995;11(03):112-116

15 van den Berg HM. A cure for hemophilia within reach. N Engl J Med 2017;377(26):2592-2593

16 Lusher JM, McMillan CW. Severe factor VIII and factor IX deficiency in females. Am J Med 1978;65(04):637-648

17 Sharma V, Khalid A, Cohen AJ. Management of pregnancy in a patient with severe hemophilia type a. AJP Rep 2013;3(01): 29-32

18 Bodrozic JN, Miljic PS, Lekovic DR, et al. Pregnancy and delivery in a woman with severe haemophilia A. Blood Coagul Fibrinolysis 2017;28(06):496-499

19 Kadir RA, Economides DL, Braithwaite J, Goldman E, Lee CA. The obstetric experience of carriers of haemophilia. Br J Obstet Gynaecol 1997;104(07):803-810
20 Chi C, Lee CA, Shiltagh N, Khan A, Pollard D, Kadir RA. Pregnancy in carriers of haemophilia. Haemophilia 2008;14(01):56-64

21 Lee CA, Chi C, Pavord SR, et al; UK Haemophilia Centre Doctors' Organization. The obstetric and gynaecological management of women with inherited bleeding disorders-review with guidelines produced by a taskforce of UK Haemophilia Centre Doctors' Organization. Haemophilia 2006;12(04):301-336

22 Davies J, Kadir RA. Mode of delivery and cranial bleeding in newborns with haemophilia: a systematic review and metaanalysis of the literature. Haemophilia 2016;22(01):32-38

23 Andersson NG, Chalmers EA, Kenet G, Ljung R, Mäkipernaa A, Chambost HPedNet Haemophilia Research Foundation. Mode of delivery in hemophilia: vaginal delivery and cesarean section carry similar risks for intracranial hemorrhages and other major bleeds. Haematologica 2019;104(10):2100-2106 